\title{
The long and the short of it: 5-HTTLPR and moral judgement
}

\author{
Diana Armbruster ${ }^{1}$, Klaus-Peter Lesch ${ }^{2}$, Alexander Strobel ${ }^{3}$
}

${ }^{1}$ Personality Psychology and Assessment, Institute of Psychology, Chemnitz University of Technology, Chemnitz, Germany

${ }^{2}$ Division of Molecular Psychiatry, Center of Mental Health, University of Wuerzburg, Wuerzburg, Germany; Laboratory of Psychiatric Neurobiology, Institute of Molecular Medicine, Sechenov First Moscow State Medical University, Moscow, Russia; Department of Psychiatry and Neuropsychology, School for Mental Health and Neuroscience (MHeNS), Maastricht University, Maastricht, The Netherlands

${ }^{3}$ Personality and Individual Differences, Faculty of Psychology, Technische Universität Dresden, Dresden, Germany

Correspondence: Diana Armbruster

Personality Psychology and Assessment, Institute of Psychology, Chemnitz University of Technology, 09120 Chemnitz, Germany

Phone: +4937153139090

Fax: +49371 53128459

E-mail: diana.armbruster@psychologie.tu-chemnitz.de 


\begin{abstract}
Differences in moral sentiments are widespread. Increasingly, their biological correlates are investigated to elucidate potential sources of divergent moral attitudes and choices. Serotonin is one such potential modulator. We investigated the effects of a functional serotonergic polymorphism, 5-HTTLPR, which was previously linked to moral choices albeit with inconsistent findings. $N=157$ healthy young adults completed a set of congruent and incongruent moral dilemmas. The set allows in addition to (1) the traditional response score an estimation of underlying (2) deontological and (3) utilitarian inclinations. While there was no main effect of 5HTTLPR on any of the three moral judgement parameters, there was an interaction effect between 5-HTTLPR and endocrine status on deontology but not on utilitarianism or the traditional score. In men and free cycling women, LL homozygotes showed reduced deontological tendencies compared to $\mathrm{S}$ allele carriers. Contrariwise, in women using oral contraceptives, LL homozygotes had increased deontology scores. Furthermore, LL genotypes in general reported less difficulty in making harmful choices, which were in addition associated with less negative emotions in this group. The findings suggest that 5-HTTLPR might be involved in modulating cognitive and emotional processes contributing to moral decisions.
\end{abstract}

Key words: 5-HTTLPR, moral judgement, deontology, utilitarianism, oral contraceptives 


\section{Introduction}

There are widespread differences in moral attitudes and choices (Ellemers et al., 2019). What is considered 'just' and 'moral' behavior varies and depends on multiple factors. In the last two decades, research efforts to investigate potential sources of these differences have increasingly included biological correlates of moral decision-making and its related processes (Garrigan et al., 2016). One prominent biological factor in this ongoing research is the neuromodulator serotonin (Siegel and Crockett, 2013) and with growing evidence for heritability of moral inclinations (Smith and Hatemi, 2021), genetic variations in the serotonergic system are the target of investigations as well.

Serotonin is linked to various factors that modulate moral decisions including harm aversion, fairness, and reciprocity (review: Siegel and Crockett, 2013). Studies investigating potential effects of selective serotonin reuptake inhibitors (SSRI), which increase serotonin availability and synaptic activity, have reported heightened cooperative and social affiliative behavior (review: Levy et al., 2014). Correspondingly, depletion of the serotonin precursor tryptophan reduces cooperation (Wood et al., 2006) and acceptance rates of unfair offers (Crockett et al., 2008). Recent work (Kanen et al., 2021) additionally points to personality differences as key moderators of tryptophan depletion effects on moral emotions in response to scenarios invoking unjust harm. In individuals with higher trait psychopathy, increased annoyance was found, while higher trait empathy was linked to increased guilt (Kanen et al., 2021).

A few studies on moral judgement have also investigated genetic variations like 5-HTTLPR, a polymorphism in the 5' regulatory region of the serotonin transporter (5-HTT) gene. The long (L) and short (S) allele of the polymorphism result in different transcriptional activities with the $\mathrm{S}$ allele leading to reduced 5-HTT transcription (Lesch et al., 1996). Regarding moral 
choices, LL homozygotes reportedly show increased endorsement of harmful actions for the greater good (Marsh et al., 2011; Martinez et al., 2020). However, another recent study found that SS homozygotes rated (impersonal) harm as more permissible (Yang et al., 2019).

Generally, the infliction of harm is seen as violation of deontological principles that reflect situation-independent moral rules (cf. Gawronski and Beer, 2017). Nevertheless, in addition to deontological inclinations, utilitarian tendencies, which focus on the outcome of an action and aim to maximize the overall benefit, guide moral decisions (cf. Conway and Gawronski, 2013). These two principles underlying moral judgement are thought to be independent (Greene, 2007) and do not necessarily have to be in conflict with each other. However, in dilemma scenarios that are widely employed in morality research (Christensen and Gomila, 2012; Ellemers et al., 2019), they are explicitly pitted against one another.

Usually, responses to moral dilemmas are scored in a single index reflecting the proportion of outcome-based decisions (i.e., decisions to inflict harm to achieve a 'greater good'). However, this traditional score does not allow an actual disentanglement of underlying moral inclinations because a decision to inflict harm might be due to reduced deontological tendencies, increased utilitarian inclinations, or both. Conway and Gawronski (2013) suggested a solution based on a process dissociation approach (Jacoby, 1991). They developed a dilemma set consisting of 10 moral scenarios each in an incongruent and a congruent version. In incongruent dilemmas, the harmful action results in an overall beneficial outcome outweighing the inflicted harm and thus bringing deontological tendencies (e.g., do no harm) in conflict with utilitarian ones (e.g., do what is best for the 'greater good'). In contrast, in congruent dilemmas the harmful action is not outweighed by the outcome and cannot be justified by either moral tendency (cf. Conway and Gawronski, 2013). So far, this approach has not been used to study potential effects of 5- 
HTTLPR on moral decisions. Thus, using the dilemma set by Conway \& Gawronski (2013) we investigated whether 5-HTTLPR was related to differences in moral judgements and whether these potential differences were due to underlying variations in deontology, utilitarianism, or both. To further elucidate potential differences in 5-HTTLPR genotype groups in moral decision-making, response time was included since increased reaction time is suggested to be indicating increased cognitive conflict (Botvinick et al., 2001). Participants also rated how difficult each decision was for them to examine whether 5-HTTLPR genotype affects the ease with which moral judgements are made. Furthermore, based on previous findings of 5-HTTLPRrelated differences in emotional reactivity (review: Jonassen and Landro, 2014) and the importance of emotions in moral decision-making (Fontenelle et al., 2015), we investigated ratings of positive and negative affect before and after completion of the experiment.

Finally, previous findings point to potential differences between men and women in moral judgement (Björklund, 2003; Banerjee et al., 2010; Capraro and Sippel, 2017) as well as 5HTTLPR $\times$ sex interaction effects on decision-making (Stoltenberg and Vandever, 2010) making sex a potential moderator of 5-HTTLPR effects on moral choices. Moreover, there is evidence that combined oral contraceptives (COC) affect social cognition (Montoya and Bos, 2017). Thus, we included endocrine status (i.e., men, free cycling women, women using COC) in our analyses.

\section{Methods}

We report how we determined our sample size, all data exclusions, all manipulations, and all measures in the study (Simmons et al., 2012). All materials, data, and analyses of this study are available online (https://osf.io/ujd7a/). The study is part of a larger project that includes additional endocrinological and peripheral-physiological assessment (data not reported here). 


\section{Participants}

Recruitment took place among the student body of the Technische Universität Dresden during classes, via flyers on campus or through online information. In total, 158 participants were recruited. Sample size was determined based on the size required for endocrine analyses (Armbruster et al., 2021) using G*Power 3.1 (Faul et al., 2007). Regarding 5-HTTLPR, the total sample size allowed the detection of effects of $\eta_{p}^{2} \approx 0.05$ with $1-\beta=.80$ and $\alpha=.05$.

We aimed to recruit students from different faculties (Supplemental Table 1). During the recruitment process, participants confirmed that they fulfilled the following criteria: German native speaker, normal or corrected to normal vision, non-smoker, no use of recreational drugs, no current psychological problems or past diagnoses of mental disorders, no severe physical impairment or illness. In addition, a demographic questionnaire assessing these variables was completed during the experimental session to verify that the criteria were being met. Due to technical problems, one session was prematurely aborted. Data on moral judgements and state affect are thus available for 157 young adults (men: $n=71,25.31 \pm 4.30$ years; women: $n=86$, $23.31 \pm 3.35$ years). Female participants had either a free menstrual cycle or used combined oral contraceptives (COC) with a 21/7 days pill regime. Free cycling women participated either during the early follicular phase (days 1-7) or late luteal phase (during the last six days before menses), while COC users participated during active pill use. Data collection took place from April until December 2019.

\section{Materials}

German translations of the dilemma set by Conway and Gawronski (2013) were used (see supplement or https://osf.io/ujd7a/). The set is comprised of 10 dilemmas, each in an incongruent 
and congruent version. In both dilemma types, participants are asked to opt for or against a suggested harmful action that will achieve a specific outcome. In incongruent dilemmas, the action's overall benefits offset concurrent harm while in congruent ones the harm inflicted outweighs the benefits. To ensure comparability, we presented the dilemmas in the same fixed random order as other studies (Conway and Gawronski, 2013; Park et al., 2016). To indicate whether they thought a proposed action appropriate or not, participants mouse-clicked a "yes" or "no" button. After each response, they were asked to rate the difficulty of making this decision on a 5-point Likert scale ranging from 1 (very easy) to 5 (very difficult).

\section{Procedure}

After arrival, participants were informed in writing about the study's goals and protocol and gave written consent. Then, they filled in a brief demographic questionnaire and gave a saliva sample for later hormone analyses (data not reported here). Subsequently, during a 5-minutes resting period, electro-cardiographic and electro-dermal activity was recorded (data not reported here). Afterwards, participants completed the Positive and Negative Affective Schedule (PANAS; Watson et al., 1988) followed by the computerized moral decision paradigm (cf. Conway and Gawronski, 2013) as described previously. After the experiment, they completed the PANAS a second time followed by three personality questionnaires (data not reported here): (1) the short version of the Rational-Experiential Inventory (Epstein et al., 1996), (2) the Interpersonal Reactivity Index (Davis, 1980), and (3) the Self-Report of Psychopathy Short Form (Neumann and Pardini, 2014). Finally, they gave two more saliva samples for hormone analyses (data not reported here) and DNA genotyping. At the end of their session, participants were thanked, debriefed, and reimbursed. The ethics committee of the Technische Universität Dresden approved study design and protocol (EK 225052019). 
Preprint

\section{Genotyping}

All participants $(N=157)$ were successfully genotyped for 5-HTTLPR. Genotype distribution was as follows: $\mathrm{LL}=69(43.9 \%), \mathrm{LS}=72(45.9 \%)$, and SS $=16(10.2 \%)$. Genotype distribution did not deviate from Hardy-Weinberg-Equilibrium $(p=.659)$. LS and SS genotypes were grouped together and contrasted with LL homozygotes.

\section{Statistical Analysis}

All analyses were performed using SPSS 27.0 for Windows (IBM Corp., New York, USA).

Moral judgements were analysed as suggested by Conway and Gawronski (2013). In incongruent dilemmas, the proportion of decisions for harmful actions, i.e., (1) outcome-based options (= traditional score) were calculated. Following, independent estimates of (2) deontology and (3) utilitarianism were computed using a process dissociation approach (Jacoby, 1991; Conway and Gawronski, 2013). The three moral parameters were entered in an analyses of variance with 5-HTTLPR (LL genotype vs. S allele carriers) and endocrine status (free cycling women vs. women using COC vs. men) as between-subjects factors.

Ancillary analyses were conducted to investigate potential effects of 5-HTTLPR on response time, difficulty ratings, and self-reported affect. Mean reaction time and difficulty ratings were calculated separately for incongruent and congruent dilemmas. Repeated measures analyses of variance (rmANOVAs) were performed with dilemma type (congruent vs. incongruent) as within-subjects and 5-HTTLPR genotype and endocrine status as between-subjects factors. In addition, response time and perceived difficulty in incongruent dilemmas were also computed independently for decisions against vs. for harmful actions and entered in rmANOVAs with response type (pro vs. contra harmful actions) as within-subjects, and 5-HTTLPR genotype and endocrine status as between-subjects factors. Furthermore, separate scores were computed for 
positive and negative affect before the experiment as well as for positive and negative affect after completion of the moral dilemma set. They were entered as $2 \times 2$ within-subjects factors in a rmANOVAs with 5-HTTLPR genotype and endocrine status as between-subjects factors. In addition, correlation analyses were conducted to investigate potential associations between affect ratings and the three moral judgement parameters.

\section{Results}

\section{Moral Judgement Parameters}

In the total sample, there was no main effect of 5-HTTLPR on the traditional moral judgement score $\left(\mathrm{F}(1,155)=0.74, p=.390, \eta_{p}^{2}=.005\right)$, deontology $\left(\mathrm{F}(1,155)=1.21, p=.273, \eta_{p}^{2}=.008\right)$ or utilitarianism $\left(\mathrm{F}(1,155)=0.40, p=.526, \eta_{p}^{2}=.003\right)$. However, there was a significant interaction between 5-HTTLPR and endocrine status (men vs. free cycling women vs. women using $\mathrm{COC})$ on deontology $\left(\mathrm{F}(2,151)=3.30, p=.039, \eta_{p}^{2}=.042\right.$; Figure 1) but not on the traditional score $(p=.743)$ or on utilitarianism $(p=.465$; Table 1$)$.

In men and free cycling women, LL homozygotes showed reduced levels of deontology compared to $\mathrm{S}$ allele carriers $\left(\mathrm{F}(1,116)=4.88, p=.029, \eta_{p}^{2}=.040\right)$. Contrariwise, in women using COC, LL homozygotes had higher levels of deontology compared to S allele carriers, although the effect did not reach significance $\left(\mathrm{F}(1,37)=3.71, p=.062, \eta_{p}^{2}=.091\right)$.

[Figure 1 and Table 1 about here] 
While there was a highly significant effect of dilemma type $\left(\mathrm{F}(1,151)=60.14, p \leq .001, \eta_{p}^{2}=\right.$ .285) with slower responses to incongruent dilemmas, there was no effect of 5-HTTLPR $\left(\mathrm{F}(1,151)=0.74, p=.392, \eta_{p}^{2}=.005\right)$. Furthermore, there were no interaction effects between 5 -HTTLPR and endocrine status $\left(\mathrm{F}(2,151)=0.08, p=.922, \eta_{p}^{2}=.001\right)$ or 5-HTTLPR and dilemma type $\left(\mathrm{F}(1,151)=0.40, p=.529, \eta_{p}^{2}=.003\right)$.

In addition, we analyzed differences in response times in incongruent dilemmas, depending on whether participants had chosen the suggested harmful action ('utilitarian' response) or decided against it ('deontological' response). There was a significant effect of response type $(\mathrm{F}(1,151)$ $=63.44, p \leq .001, \eta_{p}^{2}=.296$ ) with longer response times for deontological decisions. However, there was no effect of 5-HTTLPR $\left(\mathrm{F}(1,151)=0.72, p=.398, \eta_{p}^{2}=.005\right)$. There were also no interaction effects between 5-HTTLPR and endocrine status $\left(\mathrm{F}(2,151)=0.103, p=.902, \eta_{p}^{2}=\right.$ $.001)$ or 5 -HTTLPR and response type $\left(\mathrm{F}(1,151)=0.06, p=.802, \eta_{p}^{2} \leq .001\right)$ on response times.

\section{Difficulty Ratings}

There was again a main effect of dilemma type $\left(\mathrm{F}(1,151)=330.43, p \leq .001, \eta_{p}^{2}=.686\right)$ with incongruent dilemmas eliciting higher difficulty ratings. However, there were no 5-HTTLPR main effect $\left(\mathrm{F}(1,151)=0.25, p=.616, \eta_{p}^{2}=.002\right)$ nor 5 -HTTLPR $\times$ endocrine status $(\mathrm{F}(2,151)$ $\left.=0.27, p=.765, \eta_{p}^{2}=.004\right)$ or 5 -HTTLPR $\times$ dilemma type interaction effect $(\mathrm{F}(1,151)=1.19$, $\left.p=.276, \eta_{p}^{2}=.008\right)$ on difficulty ratings. 
In the sub-set of incongruent dilemmas, differences in difficulty ratings were analyzed depending on whether or not participants had opted for a harmful action. There was no effect of response type $\left(\mathrm{F}(1,151)=0.04, p=.852, \eta_{p}^{2} \leq .001\right)$ indicating that, overall, participants did not report greater difficulty when making harmful choices compared to deciding against it. Moreover, there was no main effect of 5-HTTLPR $\left(\mathrm{F}(1,151)=0.16, p=.694, \eta_{p}^{2}=.001\right)$ and no 5HTTLPR $\times$ endocrine status interaction effect $\left(\mathrm{F}(2,151)=0.15, p=.861, \eta_{p}^{2}=.002\right)$. While the interaction between 5-HTTLPR and response type $\left(\mathrm{F}(1,151)=3.73, p=.055, \eta_{p}^{2}=.024\right)$ was not significant, it reached significance when endocrine status was dropped from the analysis $\left(\mathrm{F}(1,155)=4.54, p=.035, \eta_{p}^{2}=.028\right)$. This indicates that in incongruent dilemmas LL genotypes rated decisions for harmful actions as less difficult than decisions against harmful options while the opposite was true for S allele carriers (Supplemental Figure 1).

\section{Positive and Negative Affect}

Analysis of PANAS data revealed a highly significant effect of affect type $(F(1,151)=926.21$, $p \leq .001, \eta_{p}^{2}=.860$ ) indicating that, overall, participants reported substantially higher levels of positive affect. There was also an effect of time $\left(\mathrm{F}(1,151)=4.95, p=.028, \eta_{p}^{2}=.032\right)$ as well as a time $\times$ affect type interaction $\left(\mathrm{F}(1,151)=92.33, p \leq .001, \eta_{p}^{2}=.379\right)$ showing decreased positive and increased negative affect after completing the moral dilemma experiment (Supplemental Figure 2). However, there was no effect of 5-HTTLPR $\left(\mathrm{F}(1,151)=0.07, p=.788, \eta_{p}^{2} \leq\right.$ .001) nor was there a 5-HTTLPR $\times$ endocrine status interaction effect $(\mathrm{F}(1,151)=0.40, p=$ $\left..673, \eta_{p}^{2}=.005\right)$ on self-reported affect. All other possible interaction effects were insignificant as well (all $\mathrm{p} \geq .294)$. 
Correlation analyses showed that only negative affect after completion of the moral dilemma set was associated with moral judgement. In the total sample, there was a negative correlation with the traditional moral dilemma score $(r=-.23, p=.004)$ and with utilitarianism $(r=-.24, p$ $=.003)$ but not with deontology $(p=.191)$. The correlations indicate that after making utilitarian choices negative affect was less pronounced. Contrariwise, there were no associations of negative affect before, or positive affect before and after the experiment with moral judgement parameters (all $p \geq .061$; see also supplemental table 2 ). The associations with negative affect after completion of the dilemma set hold up after partialling out the effects of endocrine status (traditional score: $r=-.20, p=.011$; utilitarianism: $r=-.22, p=.006$; Supplemental Table 3). Partial correlations between affect and moral judgement done separately in the two genetic groups (LL genotype / $\mathrm{S}$ allele carriers) revealed that the association between utilitarianism and reduced negative affect was more pronounced in LL homozygotes $(r=-.31, p=.011, n=69)$ compared to $\mathrm{S}$ allele carriers $(r=-.15, p=.169, n=88)$. The association with the traditional score did not reach significance in both sub-samples (LL: $r=-.21, p=.088$; S: $r=-.20, p=.068$; Supplemental Tables 4 and 5).

\section{Discussion}

Previous reports (Marsh et al., 2011; Martinez et al., 2020) have suggested that 5-HTTLPR LL homozygotes are more prone to endorse harmful actions in moral dilemma scenarios, although there are also contradictory findings (Yang et al., 2019). In our sample, we found evidence for decreased deontological inclinations underlying moral judgements in LL homozygotes. However, this effect was limited to men and free cycling women, while in COC users the opposite was found. Notably, there was no effect on the traditional moral dilemma score (i.e., the actual proportion of chosen harmful options in incongruent dilemmas) or on underlying utilitarianism. 
Although our findings are in need of replication, this suggests that 5-HTTLPR might primarily modulate sensitivity towards deontological moral principles (e.g., do no harm), but does not affect considerations of the overall outcome of a decision. Thus, the respective genetic groups did not differ in their regard for the "greater good" but varied in their readiness to inflict harm to achieve an overall beneficial result.

5-HTTLPR has long been in the focus of behavioral genetics research. Initially connected to negative emotionality and stress reactivity with higher levels in $\mathrm{S}$ allele carriers (e.g., Lesch et al., 1996; Sen et al., 2004), research expanded subsequently to gene $\times$ environment interaction studies (e.g., Canli and Lesch, 2007; Uher and McGuffin, 2008; Tiemeier et al., 2012) as well as to additional phenotypes like eating disorders (review: Rozenblat et al., 2017) or antisocial behavior (meta-analysis: Tielbeek et al., 2016). In addition to self-reports, various psycho-physiological parameters have been investigated, e.g., brain activity (review: Raab et al., 2016), peripheral electro-physiology (Brocke et al., 2006; Armbruster et al., 2009), or endocrine parameters (Miller et al., 2013).

Regarding judgements in moral dilemma scenarios, two studies have reported less endorsement of harmful actions in 5-HTTLPR S allele carriers (Marsh et al., 2011; Martinez et al., 2020). Marsh et al. (2011) suggested that the greater emotional responsiveness and reduced emotion regulation of S allele carriers might predispose them to be more reluctant to inflict harm. In our study we found no evidence that self-reported affect before as well as after completion of the dilemma set differed between the genotypes. Still, there was an association between utilitarianism and less negative affect after completion of the dilemma set in LL homozygotes. Thus, despite not reporting less overall negative affect, in LL homozygotes higher utilitarian inclinations appear to result in reduced negative affective responses. 
Contrary to the findings of Marsh et al. (2011) response times were unaffected by 5-HTTLPR indicating no differences in cognitive conflict while making moral decisions (cf. Botvinick et al., 2001). However, self-reported decision difficulty points to potential 5-HTTLPR effects. While overall difficulty ratings were not affected by 5-HTTLPR, there was an interaction between 5-HTTPR and decision type (pro or contra harmful action). Interestingly, LL genotypes reported less difficulty in making harmful choices compared to decisions against harmful options while the opposite was found in $\mathrm{S}$ allele carriers. Together with the negative association in LL genotypes between utilitarianism and negative affect after completing the experiment, these findings suggest that 5-HTTLPR might modulate cognitive and emotional processes contributing to moral decisions and thus the ease of moral decision making.

Intriguingly, oral contraceptive use interacted with 5-HTTLPR on moral judgement resulting in a reverse pattern in COC users with S allele carriers showing reduced deontology. Generally, COC reduce endogenous progesterone and estrogens while maintaining high levels of their synthetic counterparts (Burkman et al., 2011; Christin-Maitre, 2013). Despite the fact that COC have been routinely used for decades, the consequences of low endogenous and high exogenous steroid levels for downstream psychological processes are not completely understood (Lewis et al., 2019). Furthermore, unlike endogenous progesterone, synthetic analogs (progestins) also bind to the androgen receptor, albeit with varying affinity and functional efficiency (Burkman et al., 2011). Thus, despite reduced endogenous androgen levels, androgen signaling might actually be enhanced in COC users, depending on the type of progestin used in the respective COC formulation (Burkman et al., 2011; Taylor et al., 2020). 
COC use and 5-HTTLPR genotype might interact in various ways since there are multiple links between sex steroids and the serotonergic system, including 5-HTT function. Estrogens modulate serotonin synthesis, receptor binding, reuptake, and degradation (review: Del Rio et al., 2018). In most animal and human studies, estradiol has been shown to increase 5-HTT expression (review: Hernandez-Hernandez et al., 2019). While inhibitory as well as excitatory effects on overall serotonergic neurotransmission have been described for estradiol (HernandezHernandez et al., 2019), progesterone appears to be solely linked to increased serotonergic function (review: Barth et al., 2015). Progesterone also appears to modulate the effects of SSRIs on serotonin reuptake by 5-HTT (Benmansour et al., 2012). Regarding testosterone, findings are mixed with some studies reporting increased expression of genes encoding 5-HTT and tryptophan hydroxylase 2 in non-human primates after androgen administration (Bethea et al., 2014) and increased 5-HTT binding in humans after testosterone treatment (Kranz et al., 2015) while others found reduced 5-HTT binding (Jovanovic et al., 2015). Furthermore, testosterone actions on serotonergic function might vary depending on the specific outcome variable (Bethea et al., 2014). Regarding COC use, there are thus several potential driving forces behind the interaction with 5-HTLLPR that remain to be investigated.

There are several limitations to our study. Sample size was quite small for a candidate gene study. In particular, the sub-samples are too small for further analyses on, for instance, relations between 5-HTTLPR genotype and different COC formulations (Burkman et al., 2011; ChristinMaitre, 2013). Furthermore, we used a between-subject design with regard to endocrine status in women (COC use vs. free cycling). Despite its practical advantage, there are also several issues associated with this (Montoya and Bos, 2017) including potentially biased data sampling. Relatedly, we specifically recruited young adults to investigate free cycling vs. COC use. Thus, findings might not be generalizable to older populations and potential associations between 5- 
HTTLPR and later endocrine changes, which remain to be investigated. Furthermore, cultural factors need to be considered as well since our sample consisted almost exclusively of German university students, which further limits generalization. Thus, until replication, our findings need to be treated with caution.

In sum, our results suggest an interplay of 5-HTTLPR and exogenous sex steroids on moral judgements. In line with previous findings (Marsh et al., 2011; Martinez et al., 2020), LL homozygotes showed less deontological inclinations. However, this effect was limited to men and free cycling women while in women using COC 5-HTTLPR S allele carriers had reduced deontological tendencies. Since there are multiple hormonal differences between free cycling women and COC users and estradiol as well as progesterone and testosterone modulate serotonergic function, further research is needed to elucidate which hormonal components in COC modulate the interaction with 5-HTTLPR.

\section{Acknowledgement}

The authors would like to thank Lara Schreiter for her help in carrying out the lab sessions and Nicole Schraud (University of Wuerzburg, Germany) for DNA sample processing and genotyping. We would also like to express our gratitude to Dr. Gewnhi Park (Hope College, MI, USA) and Dr. Paul Conway (Florida State University, FL, USA) for providing additional information on the original study designs, which we adapted from their earlier work, and for recommendations on analyzing the moral judgement data.

\section{Conflict of interest}

The authors declare no conflict of interest. 
Preprint

\section{Funding}

The study was partly funded by the Deutsche Forschungsgemeinschaft (DFG), grant number CRC 940/2. 
Figure : Mean deontology ( \pm SEM) as a function of 5-HTTLPR genotype and endocrine status.

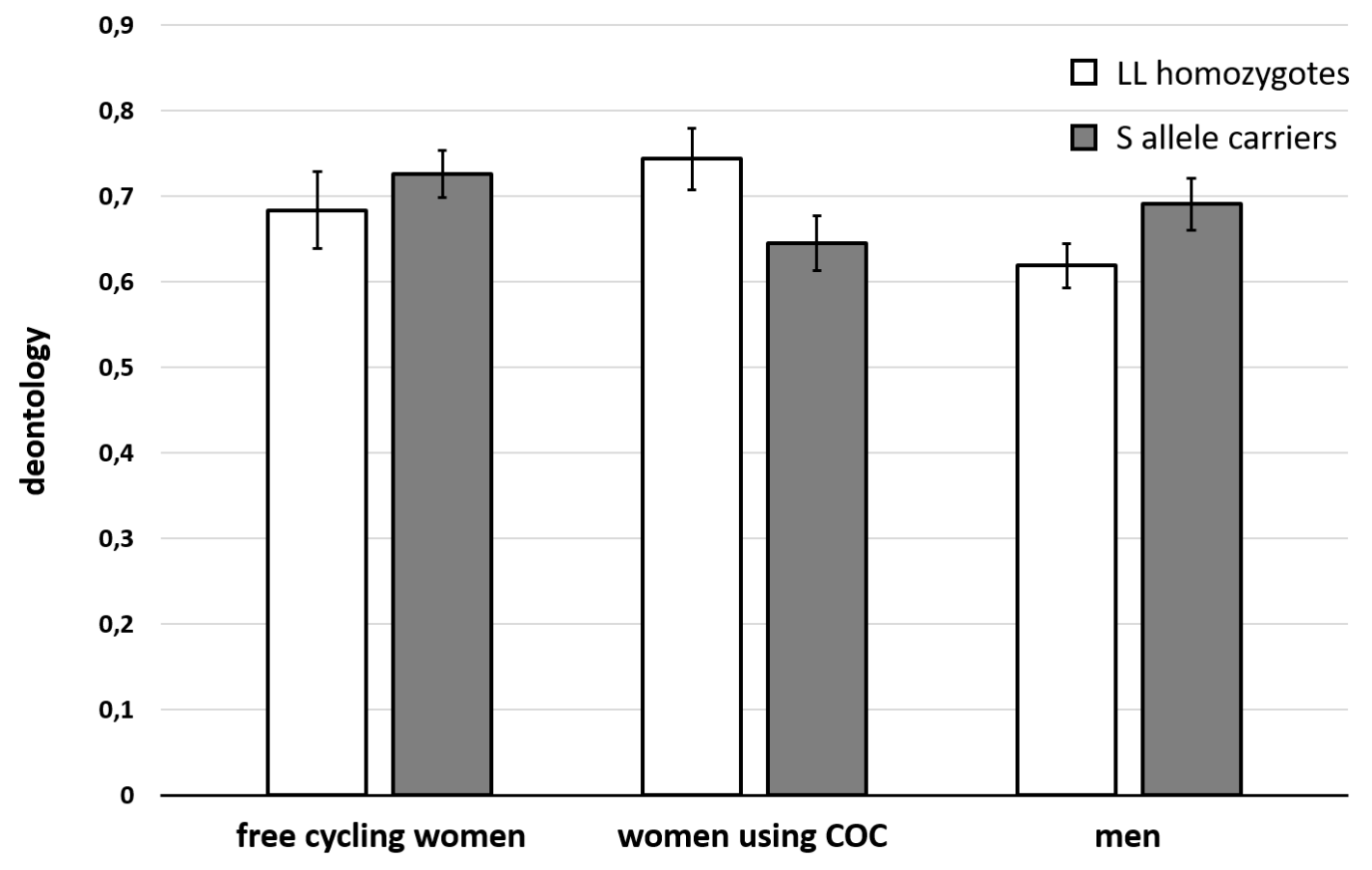

Table 1: Means ( \pm SEM) of traditional moral judgement scores as well as utilitarianism and deontology as a function of 5-HTTLPR genotype and endocrine status (free cycling women, COC users, men).

\begin{tabular}{llcccc}
\hline & 5-HTTLPR & free cycling women & women using COC & men & G $\times$ ES \\
\hline $\begin{array}{l}\text { traditional } \\
\text { score }\end{array}$ & LL & $0.588(0.044)$ & $0.600(0.038)$ & $0.650(0.025)$ & $p=.743$ \\
\cline { 2 - 6 } & $\mathrm{S}$ & $0.557(0.026)$ & $0.620(0.028)$ & $0.633(0.027)$ & \\
\hline \multirow{2}{*}{ utilitarianism } & LL & $0.412(0.048)$ & $0.471(0.032)$ & $0.447(0.024)$ & $p=.465$ \\
\cline { 2 - 6 } & S & $0.390(0.028)$ & $0.416(0.030)$ & $0.470(0.030)$ & \\
\hline deontology & LL & $0.684(0.047)$ & $0.744(0.036)$ & $0.620(0.026)$ & $p=.039$ \\
\cline { 2 - 6 } & $\mathrm{S}$ & $0.726(0.028)$ & $0.645(0.032)$ & $0.691(0.030)$ & \\
\hline
\end{tabular}

G: genotype; ES: endocrine status 


\section{References}

Armbruster, D., Kirschbaum, C. \& Strobel, A. (2021). Androgenic morality? Associations of sex, oral contraceptive use and basal testosterone levels with moral decision making. Behav Brain Res, 113196. doi:10.1016/j.bbr.2021.113196.

Armbruster, D., Moser, D. A., Strobel, A., Hensch, T., Kirschbaum, C., Lesch, K. P. \& Brocke, B. (2009). Serotonin transporter gene variation and stressful life events impact processing of fear and anxiety. Int J Neuropsychopharmacol, 12, 393-401. doi:10.1017/S1461145708009565.

Banerjee, K., Huebner, B. \& Hauser, M. (2010). Intuitive Moral Judgments are Robust across Variation in Gender, Education, Politics and Religion: A Large-Scale Web-Based Study. $J$ Cogn Cult, 10, 253-281. doi:10.1163/156853710x531186.

Barth, C., Villringerlzw, A. \& Sacher, J. (2015). Sex hormones affect neurotransmitters and shape the adult female brain during hormonal transition periods. Front Neuroscie, 9. doi:10.3389/fnins.2015.00037.

Benmansour, S., Weaver, R. S., Barton, A. K., Adeniji, O. S. \& Frazer, A. (2012). Comparison of the Effects of Estradiol and Progesterone on Serotonergic Function. Biol Psychiatry, 71, 633-641. doi:10.1016/j.biopsych.2011.11.023.

Bethea, C. L., Coleman, K., Phu, K., Reddy, A. P. \& Phu, A. (2014). Relationships between Androgens, Serotonin Gene Expression and Innervation in Male Macaques. Neuroscience, 274, 341-356. doi:10.1016/j.neuroscience.2014.05.056.

Björklund, F. (2003). Differences in the justification of choices in moral dilemmas: Effects of gender, time pressure and dilemma seriousness. Scand J Psychol, 44, 459-466. doi:10.1046/j.1467-9450.2003.00367.x.

Botvinick, M. M., Braver, T. S., Barch, D. M., Carter, C. S. \& Cohen, J. D. (2001). Conflict monitoring and cognitive control. Psychol Rev, 108, 624-652. doi:10.1037/0033295x.108.3.624.

Brocke, B., Armbruster, D., Muller, J., Hensch, T., Jacob, C. P., Lesch, K. P., Kirschbaum, C. $\&$ Strobel, A. (2006). Serotonin transporter gene variation impacts innate fear processing: Acoustic startle response and emotional startle. Mol Psychiatry, 11, 1106-1112. doi:10.1038/sj.mp.4001908.

Burkman, R., Bell, C. \& Serfaty, D. (2011). The evolution of combined oral contraception: improving the risk-to-benefit ratio. Contraception, 84, 19-34. doi:10.1016/j.contraception.2010.11.004.

Canli, T. \& Lesch, K. P. (2007). Long story short: the serotonin transporter in emotion regulation and social cognition. Nat Neurosci, 10, 1103-1109. doi:10.1038/nn1964.

Capraro, V. \& Sippel, J. (2017). Gender differences in moral judgment and the evaluation of gender-specified moral agents. Cogn Process, 18, 399-405. doi:10.1007/s10339-017-0822-9. 
Christensen, J. F. \& Gomila, A. (2012). Moral dilemmas in cognitive neuroscience of moral decision-making: A principled review. Neurosci Biobehav Rev, 36, 1249-1264.

doi:10.1016/j.neubiorev.2012.02.008.

Christin-Maitre, S. (2013). History of oral contraceptive drugs and their use worldwide. Best Pract Res Clin Endocrinol Metab, 27, 3-12. doi:10.1016/j.beem.2012.11.004.

Conway, P. \& Gawronski, B. (2013). Deontological and utilitarian inclinations in moral decision making: a process dissociation approach. J Pers Soc Psychol, 104, 216-235. doi:10.1037/a0031021.

Crockett, M. J., Clark, L., Tabibnia, G., Lieberman, M. D. \& Robbins, T. W. (2008). Serotonin modulates behavioral reactions to unfairness. Science, 320, 1739-1739. doi:10.1126/science.1155577.

Davis, M. H. (1980). A multidimensional approach to individual differences in empathy. JSAS Catalog of Selected Documents in Psychology, 10, 85.

Del Rio, J. P., Alliende, M. I., Molina, N., Serrano, F. G., Molina, S. \& Vigil, P. (2018). Steroid Hormones and Their Action in Women's Brains: The Importance of Hormonal Balance. Front Public Health, 6. doi:ARTN 141

10.3389/fpubh.2018.00141.

Ellemers, N., van der Toorn, J., Paunov, Y. \& van Leeuwen, T. (2019). The Psychology of Morality: A Review and Analysis of Empirical Studies Published From 1940 Through 2017. Pers Soc Psychol Rev, 23, 332-366. doi:10.1177/1088868318811759.

Epstein, S., Pacini, R., DenesRaj, V. \& Heier, H. (1996). Individual differences in intuitiveexperiential and analytical-rational thinking styles. J Pers Soc Psychol, 71, 390-405. doi:10.1037/0022-3514.71.2.390.

Faul, F., Erdfelder, E., Lang, A. G. \& Buchner, A. (2007). G*Power 3: A flexible statistical power analysis program for the social, behavioral, and biomedical sciences. Behav Res Methods, 39, 175-191. doi:10.3758/Bf03193146.

Fontenelle, L. F., de Oliveira-Souza, R. \& Moll, J. (2015). The rise of moral emotions in neuropsychiatry. Dialogues Clin Neuroscie, 17, 411-420.

Garrigan, B., Adlam, A. L. \& Langdon, P. E. (2016). The neural correlates of moral decisionmaking: A systematic review and meta-analysis of moral evaluations and response decision judgements. Brain Cogn, 108, 88-97. doi:10.1016/j.bandc.2016.07.007.

Gawronski, B. \& Beer, J. S. (2017). What makes moral dilemma judgments "utilitarian" or "deontological"? Soc Neurosci, 12, 626-632. doi:10.1080/17470919.2016.1248787.

Greene, J. D. (2007). Why are VMPFC patients more utilitarian? A dual-process theory of moral judgment explains. Trends Cogn Sci, 11, 322-323. doi:10.1016/j.tics.2007.06.004.

Hernandez-Hernandez, O. T., Martinez-Mota, L., Herrera-Perez, J. J. \& Jimenez-Rubio, G. (2019). Role of Estradiol in the Expression of Genes involved in Serotonin Neurotransmission: Implications for Female Depression. Curr Neuropharmacol, 17, 459-471. doi:10.2174/1570159x16666180628165107. 
Jacoby, L. L. (1991). A Process Dissociation Framework - Separating Automatic from Intentional Uses of Memory. J Mem Lang, 30, 513-541. doi:10.1016/0749-596x(91)90025-F.

Jonassen, R. \& Landro, N. I. (2014). Serotonin transporter polymorphisms (5-HTTLPR) in emotion processing Implications from current neurobiology. Prog Neurobiol, 117, 41-53. doi:10.1016/j.pneurobio.2014.02.003.

Jovanovic, H., Kocoska-Maras, L., Radestad, A. F., Halldin, C., Borg, J., Hirschberg, A. L. \& Nordstrom, A. L. (2015). Effects of estrogen and testosterone treatment on serotonin transporter binding in the brain of surgically postmenopausal women - a PET study. Neuroimage, 106, 47-54. doi:10.1016/j.neuroimage.2014.11.003.

Kanen, J. W., Arntz, F. E., Yellowlees, R., Cardinal, R. N., Price, A., Christmas, D. M., Apergis-Schoute, A. M., Sahakian, B. J. \& Robbins, T. W. (2021). Serotonin depletion amplifies distinct human social emotions as a function of individual differences in personality. Transl Psychiatry, 11, 81. doi:10.1038/s41398-020-00880-9.

Kranz, G. S., Wadsak, W., Kaufmann, U., Savli, M., Baldinger, P., Gryglewski, G., Haeusler, D., Spies, M., Mitterhauser, M., Kasper, S. \& Lanzenberger, R. (2015). High-Dose

Testosterone Treatment Increases Serotonin Transporter Binding in Transgender People. Biol Psychiatry, 78, 525-533. doi:10.1016/j.biopsych.2014.09.010.

Lesch, K. P., Bengel, D., Heils, A., Sabol, S. Z., Greenberg, B. D., Petri, S., Benjamin, J., Muller, C. R., Hamer, D. H. \& Murphy, D. L. (1996). Association of anxiety-related traits with a polymorphism in the serotonin transporter gene regulatory region. Science, 274, 15271531. doi:DOI 10.1126/science.274.5292.1527.

Levy, N., Douglas, T., Kahane, G., Terbeck, S., Cowen, P. J., Hewstone, M. \& Savulescu, J. (2014). Are You Morally Modified?: The Moral Effects of Widely Used Pharmaceuticals. Philos Psychiatr Psychol, 21, 111-125. doi:10.1353/ppp.2014.0023.

Lewis, C. A., Kimmig, A. S., Zsido, R. G., Jank, A., Derntl, B. \& Sacher, J. (2019). Effects of Hormonal Contraceptives on Mood: A Focus on Emotion Recognition and Reactivity, Reward Processing, and Stress Response. Curr Psychiatry Rep, 21, 115. doi:10.1007/s11920019-1095-z.

Marsh, A. A., Crowe, S. L., Yu, H. H., Gorodetsky, E. K., Goldman, D. \& Blair, R. J. R. (2011). Serotonin Transporter Genotype (5-HTTLPR) Predicts Utilitarian Moral Judgments. Plos One, 6. doi:10.1371/journal.pone.0025148.

Martinez, R. M., Chen, C. Y., Liao, T. T., Cheng, Y., Fan, Y. T., Chou, S. H. \& Chen, C. (2020). The Multifaceted Effects of Serotonin Transporter Polymorphism (5-HTTLPR) on Anxiety, Implicit Moral Attitudes, and Harmful Behaviors. Front Psychol, 11, 1521. doi:10.3389/fpsyg.2020.01521.

Miller, R., Wankerl, M., Stalder, T., Kirschbaum, C. \& Alexander, N. (2013). The serotonin transporter gene-linked polymorphic region (5-HTTLPR) and cortisol stress reactivity: a meta-analysis. Mol Psychiatry, 18, 1018-1024. doi:10.1038/mp.2012.124.

Montoya, E. R. \& Bos, P. A. (2017). How Oral Contraceptives Impact Social-Emotional Behavior and Brain Function. Trends Cogn Sci, 21, 125-136. doi:10.1016/j.tics.2016.11.005. 
Neumann, C. S. \& Pardini, D. (2014). Factor Structure and Construct Validity of the SelfReport Psychopathy (SRP) Scale and the Youth Psychopathic Traits Inventory (YPI) in Young Men. J Pers Disord, 28, 419-433. doi:10.1521/pedi_2012_26_063.

Park, G., Kappes, A., Rho, Y. \& Van Bavel, J. J. (2016). At the heart of morality lies neurovisceral integration: lower cardiac vagal tone predicts utilitarian moral judgment. Soc Cogn Affect Neurosci, 11, 1588-1596. doi:10.1093/scan/nsw077.

Raab, K., Kirsch, P. \& Mier, D. (2016). Understanding the impact of 5-HTTLPR, antidepressants, and acute tryptophan depletion on brain activation during facial emotion processing: A review of the imaging literature. Neurosci Biobehav Rev, 71, 176-197. doi:10.1016/j.neubiorev.2016.08.031.

Rozenblat, V., Ong, D., Fuller-Tyszkiewicz, M., Akkermann, K., Collier, D., Engels, R. C. M. E., Fernandez-Aranda, F., Harro, J., Homberg, J. R., Karwautz, A., Kiive, E., Klump, K. L., Larson, C. L., Racine, S. E., Richardson, J., Steiger, H., Stoltenberg, S. F., van Strien, T., Wagner, G., Treasure, J. \& Krug, I. (2017). A systematic review and secondary data analysis of the interactions between the serotonin transporter 5-HTTLPR polymorphism and environmental and psychological factors in eating disorders. J Psychiatr Res, 84, 62-72. doi:10.1016/j.jpsychires.2016.09.023.

Sen, S., Burmeister, M. \& Ghosh, D. (2004). Meta-analysis of the association between a serotonin transporter promoter polymorphism (5-HTTLPR) and anxiety-related personality traits. Am J Med Genet B, 127b, 85-89. doi:10.1002/ajmg.b.20158.

Siegel, J. Z. \& Crockett, M. J. (2013). How serotonin shapes moral judgment and behavior. Ann N Y Acad Sci, 1299, 42-51. doi:10.1111/nyas.12229.

Simmons, J., Nelson, L. \& Simonssohn, U. (2012). A 21 Word Solution. Available at SSRN: $\underline{\text { https://ssrn.com/abstract }=2160588 \text { or http://dx.doi.org/10.2139/ssrn.2160588. }}$.

Smith, K. \& Hatemi, P. K. (2021). Are Moral Intuitions Heritable? Hum Nat. doi:10.1007/s12110-020-09380-7.

Stoltenberg, S. F. \& Vandever, J. M. (2010). Gender moderates the association between 5HTTLPR and decision-making under ambiguity but not under risk. Neuropharmacology, 58, 423-428. doi:10.1016/j.neuropharm.2009.09.010.

Taylor, C. M., Pritschet, L. \& Jacobs, E. G. (2020). The scientific body of knowledge Whose body does it serve? A spotlight on oral contraceptives and women's health factors in neuroimaging. Front Neuroendocrinol, 60, 100874. doi:10.1016/j.yfrne.2020.100874.

Tielbeek, J. J., Linner, R. K., Beers, K., Posthuma, D., Popma, A. \& Polderman, T. J. C. (2016). Meta-Analysis of the Serotonin Transporter Promoter Variant (5-HTTLPR) in Relation to Adverse Environment and Antisocial Behavior. Am J Med Genet B, 171, 748-760. doi:10.1002/ajmg.b.32442.

Tiemeier, H., Velders, F. P., Szekely, E., Roza, S. J., Dieleman, G., Jaddoe, V. W. V., Uitterlinden, A. G., White, T. J. H., Bakermans-Kranenburg, M. J., Hofman, A., Van IJzendoorn, M. H., Hudziak, J. J. \& Verhulst, F. C. (2012). The Generation R Study: A Review of Design, Findings to Date, and a Study of the 5-HTTLPR by Environmental 
Interaction From Fetal Life Onward. J Am Acad Child Psy, 51, 1119-1135.

doi:10.1016/j.jaac.2012.08.021.

Uher, R. \& McGuffin, P. (2008). The moderation by the serotonin transporter gene of environmental adversity in the aetiology of mental illness: review and methodological analysis. Mol Psychiatry, 13, 131-146. doi:10.1038/sj.mp.4002067.

Watson, D., Clark, L. A. \& Tellegen, A. (1988). Development and validation of brief measures of positive and negative affect: the PANAS scales. J Pers Soc Psychol, 54, 10631070. doi:10.1037//0022-3514.54.6.1063.

Wood, R. M., Rilling, J. K., Sanfey, A. G., Bhagwagar, Z. \& Rogers, R. D. (2006). Effects of tryptophan depletion on the performance of an iterated Prisoner's Dilemma game in healthy adults. Neuropsychopharmacology, 31, 1075-1084. doi:10.1038/sj.npp.1300932.

Yang, Y., Wang, C., Li, X., Yu, R., Zhang, M., Xue, M., Guo, W., He, L., Gao, X. \& Gong, P. (2019). The 5-HTTLPR polymorphism impacts moral permissibility of impersonal harmful behaviors. Soc Cogn Affect Neurosci, 14, 911-918. doi:10.1093/scan/nsz060. 